\title{
A case of congenital plasmodium vivax malaria from a temperate region in central china
}

\author{
Xue Liu ${ }^{1,2+}$, Zhi-Yong Tao ${ }^{2 \dagger}$, Qiang Fang ${ }^{2}$, Xue-Mei Wang ${ }^{2}$, Hui Zhang ${ }^{1}$, Jose A Stoute ${ }^{3}$, Hui Xia ${ }^{2 *}$ and Liwang Cui ${ }^{4^{*}}$
}

\begin{abstract}
In February 2011, a rare case of congenital Plasmodium vivax malaria was diagnosed in a temperate region of Central China. An infant developed intermittent fever 20 days after delivery. Since this occurred during the nontransmission winter season in a low malaria endemic region and the infant's mother did not have a clear malaria history or showed malaria symptoms at the time of the delivery, malaria infection was not suspected at the beginning. Later, on suspicion of potential malignant haematological illness due to persistence of the fever, bone marrow smear was examined, which revealed infection by $P$. vivax parasite. This rare case of congenital vivax malaria underlines that malaria diagnosis might need to be included in the healthcare of neonates born in vivaxendemic areas.
\end{abstract}

\section{Background}

Congenital malaria is associated with significant neonatal mortality [1]. Some studies performed in hyperendemic areas suggested that congenital malaria is uncommon [2-5], whereas others have shown that it occurs significantly more frequently than was previously considered [6-9]. In comparison, reports of congenital malaria in hypoendemic areas have been even rarer. Since the symptoms of congenital malaria are usually atypical, and difficult to diagnose, it often results in delayed anti-malarial treatment [10]. Therefore, it was suggested that malaria diagnosis should be included as part of routine healthcare for all neonates in malaria hyperendemic areas $[9,11]$.

Compared to Plasmodium falciparum, Plasmodium vivax has a much wider distribution outside Africa and it extends far into the temperate zones. Recently, $P$. vivax has been shown to be not as benign as it was previously thought and is associated with complications, such as severe anaemia, respiratory distress, malnutrition, and even coma [12]. In addition, P. vivax has been found to be a major cause of morbidity in young children [13]. Besides, P. vivax can cause relapses due to the presence of long-lived latent forms in the liver, known as

\footnotetext{
*Correspondence: xiahui912@hotmail.com; luc2@psu.edu

${ }^{\dagger}$ Equal contributors

${ }^{2}$ Department of Microbiology and Parasitology, Bengbu Medical College, 2600 Donghai Dadao, Bengbu, 233030, P.R. of China

Full list of author information is available at the end of the article
}

hypnozoites. Without radical treatment to remove the hypnozoites, patients may suffer relapses. In the tropics, $P$. vivax strains are characterized by early primary infection followed by frequent relapses. In temperate areas, however, primary infection tends to occur later with long intervals and fewer and later relapses as adaptation to climatic conditions to avoid the lengthy winter when the mosquito vector is unavailable $[14,15]$. Relapse not only renders $P$. vivax resistant to eradication, but also makes diagnosis difficult during the winter season when natural malaria transmission is absent. Here is a report of a rare case of congenital vivax malaria, which occurred in a hypoendemic, temperate area during the cold winter season.

\section{Case presentation}

A 20-year old primigravida delivered a boy on February 7, 2011, in the Department Obstetrics of Bengbu First People's Hospital, Anhui Province, China. The newborn had a gestational age of 37 weeks, weighed $1.95 \mathrm{~kg}$, and the Apgar score was 10 at 1 minute. Because of low body weight compared with normal birth weight of $3.6 \pm 0.4 \mathrm{~kg}$ at the same gestational age, he was transferred to the neonatal intensive care unit immediately after delivery. He was discharged from the hospital at the age of 20 days. At home, he had fever for five hours on the same day, and was returned and admitted to the hospital for treatment. Physical and laboratory examinations were performed immediately. 
Physical examination revealed that the infant had a body temperature of $38.5^{\circ} \mathrm{C}$ and body weight of $1.97 \mathrm{Kg}$. His liver was palpable with a span of $2 \mathrm{~cm}$ both below the right costal margin and below the sternum, while the spleen was not palpable. Coarse breath sounds without rales were heard over both lung fields. There was no evidence of jaundice. Laboratory blood test results showed that the infant had a white blood cell (WBC) count of $34.4 \times 10^{9} / \mathrm{L}$ with $39.5 \%$ polymorphonuclear leukocytes and $52.2 \%$ lymphocytes, and a platelet (PLT) count of $57 \times 10^{9} / \mathrm{L}$. His haemoglobin (Hb) level was $147 \mathrm{~g} / \mathrm{L}$. He had a total bilirubin level of $295.6 \mu \mathrm{mol} / \mathrm{L}(\leq 205 \mu \mathrm{mol} / \mathrm{L}$ as normal) and direct bilirubin level of $16.5 \mu \mathrm{mol} / \mathrm{L}$ $(\leq 34 \mu \mathrm{mol} / \mathrm{L}$ as normal). Blood cultures were performed and the result was negative.

The admission diagnosis was upper respiratory tract infection associated with low body weight. The infant received intravenous injections of the antibiotic cefoperazone (0.1 g, twice daily) for 12 days. Meanwhile, his axillary temperature was monitored every four hours. Despite the treatment, he still showed an intermittent fever (Figure 1). Blood routine tests were ordered on the $2^{\text {nd }}, 4^{\text {th }}, 8^{\text {th }}, 12^{\text {th }}$, and $19^{\text {th }}$ day since admission. On the $8^{\text {th }}$ day of antibiotic treatment, his WBC count returned to the normal range, but his $\mathrm{Hb}$ and PLT count continuously decreased (Table 1). A malignant haematological illness was suspected, and a bone marrow aspiration was conducted. Surprisingly, examination of the bone marrow smear revealed $P$. vivax parasitized erythrocytes (Figure 2A). This finding was later verified by nested PCR using DNA isolated from the blood film (Figure 2B) [16].

The infant was diagnosed as having congenital malaria caused by $P$. vivax, a rare event in this area. Antibiotics were immediately discontinued and anti-malarial treatment was begun. He was given oral chloroquine phosphate (CQ) at $25 \mathrm{mg} / \mathrm{kg}$ for three days. Since parasites were not completely cleared on day 3 , additional threeday treatment at $12 \mathrm{mg} / \mathrm{kg}$ was given. Since the initiation of CQ treatment, he became afebrile (Figure 1). One week later, his $\mathrm{Hb}$ level rose to $98 \mathrm{~g} / \mathrm{L}$ (Table 1). He became aparasitaemic seven days after CQ treatment was started. He was discharged on the same day.

During the anti-malarial treatment of the infant, his mother also received examinations for malaria infection.
Table 1 Results of blood routine tests of the infant

\begin{tabular}{|c|c|c|c|c|c|}
\hline Day* & ${ }^{*} \mathrm{WBC}\left(\times 10^{9} / \mathrm{L}\right)$ & $\mathrm{Hb}(\mathrm{g} / \mathrm{L})$ & $\operatorname{RBC}\left(\times 10^{12} / \mathrm{L}\right)$ & ) Hematocrit(\%) & $\operatorname{PLT}\left(\times 10^{9} / \mathrm{L}\right)$ \\
\hline 2 & 34.4 & 147 & 4.32 & 54.0 & 57 \\
\hline 4 & 12.7 & 142 & 4.55 & 47.3 & 46 \\
\hline 8 & 8.6 & 87 & 2.72 & 17.1 & 36 \\
\hline 12 & 7.3 & 78 & 2.45 & 24.5 & 141 \\
\hline 19 & 8.0 & 98 & 3.23 & 32.5 & 138 \\
\hline
\end{tabular}

*Day since the infant was readmitted to the hospital. Anti-malarial treatment started on day 12

Two blood smears obtained at one week's interval were both microscopically negative. She was not given antimalarial treatment. In retrospect, the infant's mother recalled that she had an intermittent fever for about a week in the $6^{\text {th }}$ month of her pregnancy, but the symptoms were resolved without anti-malarial treatment. Two follow-up visits at 6 and 12 months showed that both the infant and mother did not develop further malaria symptoms during this period.

\section{Conclusions}

In recent years, $P$. vivax has become the predominant malaria parasite species in China [17]. Especially in the temperate central provinces where malaria transmission is unstable, $P$. vivax was the only species responsible for malaria outbreaks occurred recently [18]. With considerable control efforts, the annual malaria incidence rate in Anhui Province was significantly reduced in recent years [17]. In city, P. vivax malaria is rare, especially during the winter when malaria transmission is interrupted. The $P$. vivax parasite in this region is typical of temperate strains with a long relapse pattern. Occasionally, patients develop malaria during the non-transmission season, which often makes proper malaria diagnosis difficult. Febrile patients during winter time are normally not considered for diagnosis of malaria infection. In the present case, the patient was a newborn, and the onset of malaria symptoms occurred when he was 20 days old. Since the average temperature in February in Bengbu city was $3.8^{\circ} \mathrm{C}$, natural transmission of malaria could not have occurred. In addition, his mother was a local resident without a travel history outside of Anhui province during her pregnancy. During her pregnancy, she did not receive anti-malarial treatment. Therefore, it was

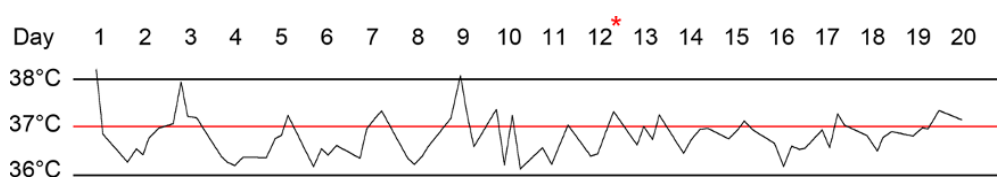

Figure 1 The infant's body temperature. Shown here is an intermittent fever pattern prior to the initiation of $C Q$ treatment on the $12^{\text {th }}$ day anti-malarial(shown as an asterisk) and subsequent resolution of the fever. 

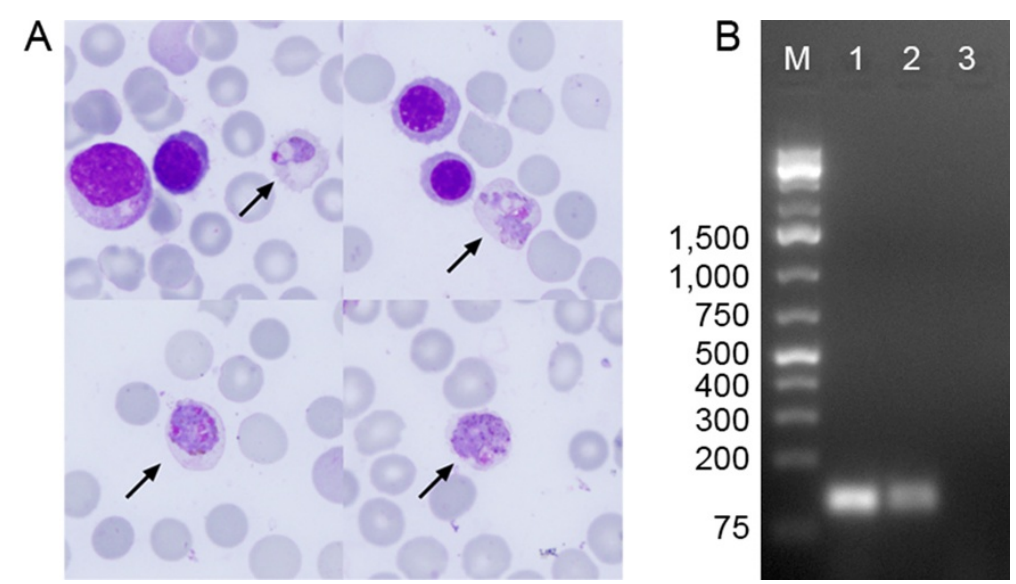

Figure 2 Diagnosis of the congenital malaria. (A) Giemsa-stained film of the bone marrow aspiration from the infants showing $P$. vivax infected erythrocytes (arrows, magnification 1,000X). (B) Confirmation of the diagnosis by nested PCR showing the $\sim 125$ bp PCR band specific for P. vivax. M, DNA Ladder, Lane 1, P. vivax positive control; Lane 2, DNA extracted from the infant's bone marrow film; Lane 3, Negative control.

impossible to connect the infant's fever to malaria infection at the beginning. Only when haematological examination was performed on suspicion of haematological illness, he was diagnosed of having vivax malaria infection. Since natural transmission was extremely unlikely, the only possibility was transmission of the parasite from the mother to the foetus during her pregnancy or at the time of delivery.

Malaria infection during pregnancy can have a huge impact on both the mother and the foetus. It can lead to still birth, premature delivery, and low birth weight. Evidently, congenital malaria is another serious challenge for neonates' healthcare [1,11]. For babies born to mothers with active blood stage malaria infection or history of malaria infection during pregnancy, aggressive monitoring of congenital malaria should be adopted. Currently, there is little information about the prevalence of congenital $P$. vivax malaria [19], and equally unknown is the impact of congenital malaria on neonates. Therefore, this case of congenital vivax malaria during a non-transmission season in a temperate region cautions that neonates born in malaria-endemic regions with fever should be examined for congenital malaria, especially when anemia or thrombocytopenia occurs.

Since primaquine is contraindicated in pregnancy, there is no radical malaria treatment strategy for pregnant women with absolute safety to the foetus. Although it has been shown that weekly CQ prophylaxis against vivax malaria in pregnant women is safe and effective in preventing vivax malaria [20], chemoprophylaxis for pregnant women living under risk of $P$. vivax has not been widely used [11]. In regions, such as the central provinces of China, where clinical CQ resistance in $P$. vivax malaria has not been documented and in vitro assays showed that $P$. vivax was sensitive to CQ [21],
CQ prophylaxis against vivax malaria during pregnancy might be offered to high-risk populations. In addition, considering the effects of congenital malaria on the foetus and infant $[1,13]$, antenatal care in malaria endemic areas to detect and treat malaria episodes during pregnancy needs to be actively implemented.

\section{Competing interests}

The authors declare that they have no competing interests.

\section{Acknowledgements}

This work was supported by the Key Program of Natural Science Foundation of the Anhui Higher Education Institutions (no. KJ2012A200), a grant U19AI089672 from NIAID, NIH, and the Key Project of Chinese Ministry of Education (no. 211079).

\section{Author details}

${ }^{1}$ Bengbu First People's Hospital, 229 Tu Shan Road, Bengbu, 233010, P. R. of China. ${ }^{2}$ Department of Microbiology and Parasitology, Bengbu Medical College, 2600 Donghai Dadao, Bengbu, 233030, P.R. of China. ${ }^{3}$ Department of Medicine, Pennsylvania State University College of Medicine, 500 University Drive, MC H036, Room C6860, Hershey, PA 17033, USA. ${ }^{4}$ Department of Entomology, Pennsylvania State University, 537 ASI Building, University Park, PA 16802, USA.

\section{Authors' contributions}

$\mathrm{XL}$, ZYT drafted the manuscript. $\mathrm{XL}, \mathrm{ZYT}$ and $\mathrm{QF}$ contributed expertise in the laboratory diagnosis and specie identification. XMW, HZ carried out data collection and epidemiological study. HX conceived this case report. HX, LC and IS contributed to case analysis. All authors have read and approved the final manuscript.

Received: 23 March 2012 Accepted: 6 June 2012

Published: 6 June 2012

\section{References}

1. Desai M, ter Kuile FO, Nosten F, McGready R, Asamoa K, Brabin B, Newman RD: Epidemiology and burden of malaria in pregnancy. Lancet Infect Dis 2007, 7:93-104.

2. Lamikanra OT: A study of malaria parasitaemia in pregnant women, placentae, cord blood and newborn babies in Lagos, Nigeria. West Afr J Med 1993, 12:213-217. 
3. Adachi M, Yuda M, Ando K, Sakurai M, Chinzei Y: Scant parasitemia in BALB/c mice with congenital malaria infection. J Parasito/ 2000, 86:10301034.

4. Sule-Odu AO, Ogunledun A, Olatunji AO: Impact of asymptomatic maternal malaria parasitaemia at parturition on perinatal outcome. $J$ Obstet Gynaecol 2002, 22:25-28.

5. Ouedraogo A, Tiono AB, Diarra A, Bougouma EC, Nebie I, Konate AT, Sirima SB: Transplacental transmission of Plasmodium falciparum in a highly malaria endemic area of Burkina Faso. J Trop Med 2012, 2012:109705.

6. Larkin GL, Thuma PE: Congenital malaria in a hyperendemic area. Am J Trop Med Hyg 1991, 45:587-592.

7. Fischer PR: Congenital malaria: an African survey. Clin Pediatr (Phila) 1997 36:411-413.

8. Obiajunwa PO, Owa JA, Adeodu OO: Prevalence of congenital malaria in Ile-ife, Nigeria. J Trop Pediatr 2005, 51:219-222.

9. Runsewe-Abiodun IT, Ogunfowora OB, Fetuga BM: Neonatal malaria in Nigeria-a 2 year review. BMC Pediatr 2006, 6:19.

10. Menendez C, Mayor A: Congenital malaria: the least known consequence of malaria in pregnancy. Semin Fetal Neonatal Med 2007, 12:207-213.

11. Rijken MJ, McGready R, Boel ME, Poespoprodjo R, Singh N, Syafruddin D, Rogerson S, Nosten F: Malaria in pregnancy in the Asia-Pacific region. Lancet Infect Dis 2012, 12:75-88.

12. Price RN, Tjitra E, Guerra CA, Yeung S, White NJ, Anstey NM: Vivax malaria: neglected and not benign. Am J Trop Med Hyg 2007, 77:79-87.

13. Poespoprodjo JR, Fobia W, Kenangalem E, Lampah DA, Hasanuddin A, Warikar N, Sugiarto P, Tjitra E, Anstey NM, Price RN: Vivax malaria: a major cause of morbidity in early infancy. Clin Infect Dis 2009, 48:1704-1712.

14. Garnham PCC: Malaria: Principles and Practice of Malariology. In Malaria parasites of man: life-cycles and morphology. Edited by Wernsdorfer WH, Sir McGregor I. London: Churchill Livingstone; 1988:61-96.

15. White NJ: Determinants of relapse periodicity in Plasmodium vivax malaria. Malar J 2011, 10:297.

16. Snounou G, Viriyakosol S, Zhu XP, Jarra W, Pinheiro L, do Rosario VE, Thaithong S, Brown KN: High sensitivity of detection of human malaria parasites by the use of nested polymerase chain reaction. Mol Biochem Parasitol 1993, 61:315-320.

17. Zhou SS, Wang Y, Li Y: Malaria situation in the People's Republic of China in 2010. Chin J Parasitol Parasit Dis 2011, 29:401-403.

18. Xu BL, Su YP, Shang LY, Zhang HW: Malaria control in Henan Province, People's Republic of China. Am J Trop Med Hyg 2006, 74:564-567.

19. Pengsaa K: Congenital malaria in Thailand. Ann Trop Paediatr 2007 27:133-139.

20. Villegas L, McGready R, Htway M, Paw MK, Pimanpanarak M, Arunjerdja R, Viladpai-Nguen SJ, Greenwood B, White NJ, Nosten F: Chloroquine prophylaxis against vivax malaria in pregnancy: a randomized, doubleblind, placebo-controlled trial. Trop Med Int Health 2007, 12:209-218.

21. Lu F, Gao Q, Chotivanich K, Xia H, Cao J, Udomsangpetch R, Cui L, Sattabongkot J: In vitro anti-malarial drug susceptibility of temperate Plasmodium vivax from central China. Am J Trop Med Hyg 2011, 85:197201.

doi:10.1186/1475-2875-11-182

Cite this article as: Liu et al:: A case of congenital plasmodium vivax malaria from a temperate region in central china. Malaria Journal 2012 11:182.

\section{Submit your next manuscript to BioMed Central and take full advantage of:}

- Convenient online submission

- Thorough peer review

- No space constraints or color figure charges

- Immediate publication on acceptance

- Inclusion in PubMed, CAS, Scopus and Google Scholar

- Research which is freely available for redistribution 